\title{
Development of a Soundproof Device for 950 Watt rated Portable Generators
}

\section{${ }^{1}$ MUSA NICHOLAS AKHAZE; ENOCH JOHN}

\author{
Mechanical Engineering Department, Federal University of Technology, \\ Minna, Niger State, Nigeria \\ *Corresponding author. Email address- Madonick1 @yahoo.com
}

\begin{abstract}
The noise emanating from generators has adverse effects on our health. In view of this, this paper reports the development of soundproof device for 950Watt rated generators which are widely used portable generators. Performance evaluation of the soundproof device was carried out, and the sound pressure level of the generator was reduced by $7.64,6.24,6.82,8.72$ and $8.68 \mathrm{~dB}$ at distances of $0.70,1.40,2.10,2.80$ and $3.50 \mathrm{~m}$ from the generator respectively. (C) JASEM
\end{abstract}

http://dx.doi.org/10.4314/jasem.v20i1.10

KEYWORDS: Generator, soundproof device, sound pressure level, enclosure, open environment

\section{INTRODUCTION}

In most developing countries like Nigeria, one of the alternatives, that is mostly explored to forestall the problem of erratic power supply, is the use of packaged generators. These packaged generators have an advantage in terms of mobility and ease of deployment to business sites, the installation and startup times are equally short. As a disadvantage, these generators are relatively expensive to run with the current price regime of petroleum products and fuels attendant pollution of the environment resulting from flue gas discharge to the environment and noise pollution cannot be ruled out. The attendant consequence of the foregoing, is that people and the environment are being exposed to noise and vibration in excess of sixteen hours per day (Okpighe, 2015)

According to Chandrashekara et al (2014) noise is an unwanted sound . It is a hazard that we expose ourselves to every day without consideration (Banks, 1997). Noise is usually regarded as one of the factors threatening our living environments (Ahmed et al, 2010). Although Industrial machinery, air/surface transportation and construction activities are main contributors in noise production or"noise pollution"(Hawkins, 2014) generators contribute so much to this noise. As asserted by Parvathi et al,(2003) and Todd et al(2013), these generators emit very high levels of noise in addition to noxious gas emission, making generator noise one of the major contributions to environmental noise pollution. Noise from generator arises from three sources and these are engine air flow interactions, combustion noise and mechanical noise (Krishna and Wegrzyn, 1999). Noise can cause physical problems such as permanent hearing loss, as well as psychological traumas, like Stress. Kuku et al(2012) asserted that the use of generator as alternative source of electricity power is almost, if not a norm in the Nigerian society today and the growing concerns is to avoid the noise from these generating set. However, Olayinka (2013) stated that due to the ignorance of Nigerians on the fact, there exist a close nexus between noise pollution and sustainable city, little or no attention is paid to the control of noise pollution in Nigeria. Looking into the serious and disastrous effects of noise pollution on human life, it is essential to take preventive and protective measures (Ijaiya,2014)

Since the use of generator as alternative, cannot be presently avoided, there is a great need to control the noise. The mostly widely used generators among the portable ones, is the one rated $950 \mathrm{~W}$, despite its low wattage. The reason could be attributed to its low cost irrespective of the make, compare to others. So the aim of this work is to use passive control method to develop a soundproof device for $950 \mathrm{~W}$ rated generator that is to some extent affordable and use by all and sundry.

\section{MATERIALS AND METHODS}

The following materials were used for the construction of the soundproof device: Medium DensityFireboard (MDF) 2. Polyurethane foam, 3. fan 4. Screw and gums 5.Electric cable and sockets 6.Hinges 7.Heat resistance rubber pipe and 8. Sound level meter manufactured in Taiwan by Exteck Instrument Corporation

Three pairs of panel with each pair having sizes of $686 \mathrm{mmx} \quad 444 \mathrm{~mm}$, 686mmx480mm and $480 \mathrm{~mm} \times 444 \mathrm{~mm}$, padded with polyurethane foam of thickness $25 \mathrm{~mm}$ were fabricated from MDF of 
thickness $25 \mathrm{~mm}$. The outer dimension of the enclosure is $686 \mathrm{mmx} 480 \mathrm{mmx} 444 \mathrm{~mm}$.

Determination of the volume of the space in the enclosure

The thickness of the foam, $t_{\mathrm{f}}=25 \mathrm{~mm}$ and the thickness of MDF, $\mathrm{t}_{\mathrm{m}}=25 \mathrm{~mm}$

Inner length of the enclosure, $\mathrm{l}_{\mathrm{i}}=686$ $(25+25+25+25)=586 \mathrm{~mm}$, Inner width or breadth of the enclosure, $b_{i}=480-(25+25+25+25)=380 \mathrm{~mm}$, Inner height of the enclosure,

$\mathrm{h}_{\mathrm{i}}=444-(25+25+25+25)=344 \mathrm{~mm}$

The volume of the space in the enclosure,

$$
\begin{aligned}
& \mathrm{V}_{\mathrm{S}}=\mathrm{l}_{\mathrm{i}} \times \mathrm{b}_{\mathrm{i}} \times \mathrm{h}_{\mathrm{i}} \\
& \mathrm{V}_{\mathrm{S}}=0.586 \times 0.380 \times 0.344=0.077 \mathrm{~m}^{3}
\end{aligned}
$$

Determination of flow rate of the required cooling air, The rated power of the generator $=950 \mathrm{~W}$

The output power of the generator on $3 / 4$ load $=3 / 4$ $\mathrm{x} 950=712.5 \mathrm{~W}$, Five experimental trials were carried out on the $950 \mathrm{~W}$ generator on $3 / 4$ load. On the average, the generator consumes 0.5 litres of petrol per hour.

So the energy that is put into the system, $\mathrm{P}_{\mathrm{i}}=\frac{\rho V C}{t}$

.Where $\rho$ is the density of petrol $=737 \mathrm{~kg} / \mathrm{m}^{3}, \mathrm{v}$ is the volume of petrol $=0.5$ litre $\left(0.0005 \mathrm{~m}^{3}\right)$ and $\mathrm{t}$ is the time $=1$ hour $(60 \times 60$ seconds $)$ and $\mathrm{C}$ is the calorific value of petrol $=44 \mathrm{MJ} / \mathrm{Kg}$

$\mathrm{P}_{\mathrm{i}}=\frac{0.0005 \times 737 \times 44 \times 10^{6}}{60 \times 60}=4503.89 \mathrm{~W}$

Assuming $60 \%$ of the energy is lost through the exhaust, so the energy available from the petrol that is put into the generator $\mathrm{P}_{\mathrm{a}}=\frac{40 \times 4503.89}{100}=1801.56 \mathrm{~W}$, So the energy lost by the generator to the enclosure, $\mathrm{Q}_{\mathrm{e}}=1801.56-712.5=1089.06 \mathrm{~W}$

This is the amount of heat that should be extracted from enclosure by the fan.

The air flow is given as, $\dot{M}=\frac{\mathrm{Qe}}{\operatorname{Cpx} \Delta \mathrm{T}}$

Where $\mathrm{Cp}$ is the specific heat capacity of air at constant volume which is $1 \mathrm{~kJ} /\left(\mathrm{kg}^{0} \mathrm{C}\right)$ and $\Delta \mathrm{T}$ is the change in temperature between the air inside the enclosure and outside ambient air
$\dot{\mathrm{M}}=\frac{1089.06}{28000}=0.039 \mathrm{Kg} / \mathrm{s}$

Assuming a hot day, the outside ambient air temperature would be $37^{\circ} \mathrm{C}$. Also assuming the air temperature inside the enclosure should not exceed $65^{\circ} \mathrm{C}$, in line with work of Banks, (1999).

The volumetric flow rate or discharge of the air is given as

$\mathrm{Q}=\frac{\dot{\mathrm{M}}}{\rho \mathrm{a}}$

Where $\rho$ a is the density of air at $65^{\circ} \mathrm{C}=1.045 \mathrm{~kg} / \mathrm{m}^{3}$ $\mathrm{Q}=\frac{0.039}{1.045}=0.037 \mathrm{~m}^{3} / \mathrm{s}$

This is the quantity of air that would be supplied by the fan and the dimension of the inlet of the enclosure through which the air will be supplied is $90 \mathrm{~mm} \mathrm{x}$ $90 \mathrm{~mm}$.

The velocity at which this air is supplied, $\mathrm{U}=\frac{Q}{A_{d}}$ (5)

Where $A_{d}$ is the area of the air duct $=0.09 \times 0.09=$ $0.0081 \mathrm{~m}^{2}$

$\mathrm{U}=\frac{0.037}{0.0081}=4.57 \mathrm{~m} / \mathrm{s}$,

Selection of the fan: Since the quantity of air that would be supplied by the fan has been determined to be $0.037 \mathrm{~m}^{3} / \mathrm{s}$, Two fans were selected having the discharge of $0.037 \mathrm{~m}^{3} / \mathrm{s}$, with one drawing fresh air into the enclosure to cool and the other extracting hot air from the enclosure.

Assembly of the soundproof device: The fabricated three pairs (6) panels padded with foam were assembled with screws and hinges to form the enclosure, making one of the six padded panels into a hinged door, another into the floor or base where the generator is placed. Fitted to the panel which form the right hand side and the one which form the left hand side of the device as shown in plate I, are the two fans and the heat resistance pipe which is attached to the exhaust of the generator, respectively. The pictorial views of the soundproof device with opened and closed door are shown in plates I and II respectively. 


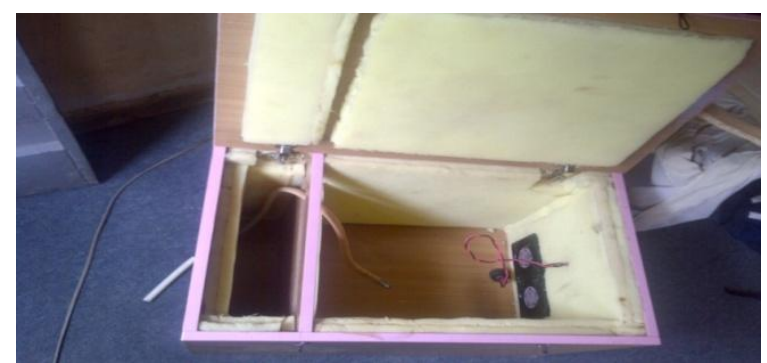

Plate: I The opened soundproof device .

Performance evaluation of the soundproof device: 950W rated Honda generator was put on and placed inside the soundproof device and was allowed to run on three quarter load, for 20 minutes and as it was running, the sound level meter manufactured in Taiwan by Exteck Instrument Corporation was switched on and used to measure the sound pressure level in decibel $(\mathrm{dB})$ at distances of $0.70 \mathrm{~m}, 1.4 \mathrm{~m}$, $2.1 \mathrm{~m}, 2.8 \mathrm{~m}$ and $3.5 \mathrm{~m}$ from the generator five times, with the average value taken for each of five different distances from the soundproof device. The same procedure was repeated when the generator was placed in an open environment.

\section{RESULTS AND DISCUSSION}

The variation of sound pressure level of the generator run in an open environment and in the soundproof device with the distance of measurement from the generator is shown in Figure 1.

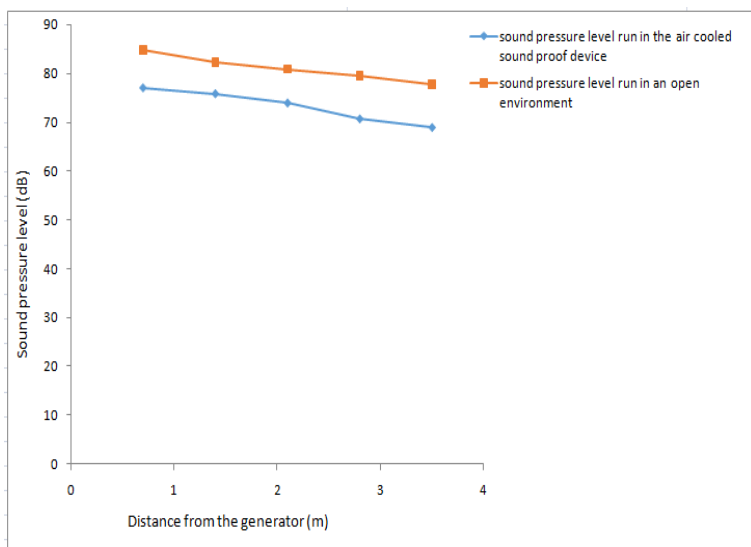

Fig 1: The variation of sound pressure level of the generator run in an open environment and in the soundproof device with the distance of measurement from the generator

It can be seen from figure 1, that the sound pressure level decreases as the distance from the generator increases for both running the generator in an open environment and in the soundproof device. The values of the sound level pressure of the generator

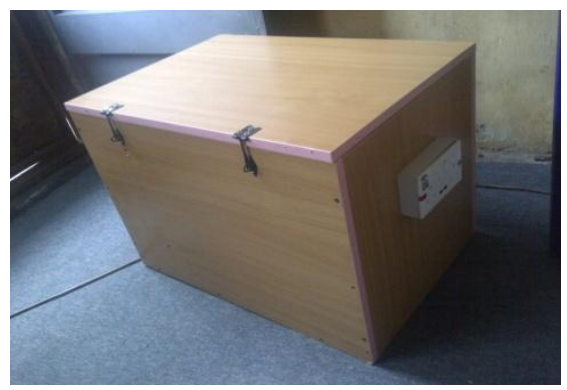

Plate: II The closed soundproof device

range between 84.70 and $77.62 \mathrm{~dB}$ as the measured distances range between 0.70 and $3.50 \mathrm{~m}$, when it was run in open environment. Exposure to this range of sound pressure level could be classified as high risk as defined by Yesufu, et al, (2013). A continuous exposure to this kind of noise or sound within this range of sound pressure level, without a corresponding period of recouping will certainly lead to one of the health related effects of noise as suggested by Agarwal and Swami(2009) stated by Anomohanran(2013). There are reductions in sound pressure level measured for the generator run in the soundproof device at distances of $0.70,1.40,2.10$, 2.80 and $3.50 \mathrm{~m}$ by $7.64,6.24,6.82,8.72$ and $8.68 \mathrm{~dB}$ respectively. This trend of reduction of sound pressure level is similar to the trend observed in Kuku et al(2012) work.

Conclusion: The use of portable generator is unavoidable as it is the readily available, affordable and alternative energy source for developing economies like Nigeria. However, the noise pollution from these generators, which are detrimental to our health, can be mitigated to a reasonable extent by the use of the developed soundproof device, which is simple in production. The soundproof device could reduce sound pressure level of the $950 \mathrm{~W}$ rated generator by $7.64,6.24,6.82,8.72$ and $8.68 \mathrm{~dB}$ at distances of $0.70,1.40,2.10,2.80$ and $3.50 \mathrm{~m}$ from the generator respectively.

\section{REFERENCES}

Ahmed, A.; Medhat A F .; Hoda, S S(2010). Noise prediction for outdoor cooling systems; case study. Journal of American Science 11(6): 899905 .

Anomohanran, O (2013). Evaluation of environmental noise pollution in Abuja, The capital city of Nigeria IJRRAS 14 (2) :470-476.

Banks, J E (1997). Optimal design of an enclosure for portable generator. M.Sc Thesis submitted to 
the faculty of of the Virginia Polytechnic Institute and State University, Blacksburg, Virginia

Chandrashekara, K.;Yogish, H.; Srinidhi, R.; Harsha, B P.; Sharma, P R(2014).

A comparative study of sound pressure level (SPL) generated in CI DI diesel engine run on petrodiesel and biodiesel blends. International Journal of Thermal Technologies 4 (3):208-213.

Hawkins, T G (2014). Studies and research regarding sound reduction materials with the purpose of reducing sound pollution. M.Sc Thesis submitted to Faculty of California Polytechnic State University, San Luis Obispo.

Ijaiya, H(2014). The legal regime of noise pollution in Nigeria Beijing Law Review (BLR) 5(1): $1-6$.

Krishna, C R.; Wegrzyn, J E(1999). Survey of noise suppression systems for engine generator sets. Informal Reports. Energy Efficiency and Conservation Division. Department of of Applied Science, Brookhaven National Laboratory, Brookhaven Science Associates Upton, Long Island, New York 11973 pp1-28

Kuku, R O.; Raji, N A. ; Bello, T(2012). Development and performance evaluation of a sound proof enclosure for portable generators. Research Journal of Applied Sciences, Engineering and Technology 4(16): 2600.

Okpighe, S O(2015). Review of noise suppression in packaged generators. Journal of Scientific Research and Reports. 5(5): 361-374.

Olayinka, O S(2013). Effective noise control measures and sustainable development in Nigeria. World Journal of Environmental Engineering, 1(1):5-15.

Parvathi, K.; Navaneetha, A G (2003). Studies on control of noise from portable power generator. Proceedings of the Third International Conference on Environment and Health, Chennai, India: $328-338$.

Told, J Z.; Chagok, N M D.; Domtau, LD.; Fom, T P.; Ngadda, Y H (2013). Sound pressure level, power level, noisiness and perceive noise level of some commonly used generators in Pankshin metropolis of Plateau State, Nigeria. Civil and Environmental Research. 3(9) : 45-52.

Yesuf, A L,.;Ana, G R.; Yawei, Z.; Umar, O $\mathrm{Z}$ (2013). Work environment noise levels and risk locations in two selected commercial areas in Ibadan, Nigeria. Global Journal of Medical Research Interdisciplinary 13(6):25-34. 